\title{
Effect of Wind Environment on High Voltage Transmission Lines Span
}

\author{
Ogbogu Nelson \\ Dept. of Electrical Electronic Engineering \\ University of Port Harcourt \\ Rivers State, Nigeria
}

\author{
Oniyeburutan Ebakumo Thomas \\ Dept. of Electrical Electronic Engineering \\ University of Port Harcourt, \\ Rivers State, Nigeria
}

\begin{abstract}
This paper examines the effects of wind environment on high voltage transmission lines span. Proper analysis of wind and its effects is important on high voltage transmission lines for the purpose of continuity and quality of electrical services. Strong wind has the potential of causing unexpected damages to conductors and thus erupting power transmission of the system. Various literatures on wind effects on high voltage transmission lines were reviewed. The various effects of wind environment on high voltage transmission lines span as well as possible solutions to these effects were examined.
\end{abstract}

Keywords: Wind effect, Electrical, Transmission Line, Span, Sag, Tension

\section{INTRODUCTION}

Transmission of electricity is the process of transporting electricity from the power station where it is generated to different places or point where it is consumed, such as our homes and various industries. Transmission of electricity is done through the electricity conducting wires or cables called transmission lines. These transmission lines and substations play a central role in the transmission system [1]. Power system comprises of three entities, power generation, transmission and distribution. Among these entities, the ineffectiveness in transmission part contributed to most of the losses. These losses depend on the resistance, inductance and capacitance, which are termed as the constants of a transmission line [2]. Therefore appropriate modeling and care is of paramount while designing and erecting a high voltage transmission system. The subsequent performance of the transmission depends on the kind of transmission model used in the system [3]. Instability on transmission line are caused by various factors such as sag, aerodynamic drag, wind, tension, ice loading, conductor size, insulators, line span e.t.c. Strong wind may cause unexpected damage to the power transmission systems, Fig. 1 [4]. Wind speed and turbulence intensity are greatly affected by terrain and climate, Fig. 2 [5]. In terrains where there are mountainous, the terrain effect is manifested in the speed-up of local wind owing to the narrow path caused by the mutual aperture of location of mountain ridge and wind direction. Thus careful study and design are needed when attempting to construct power transmission line in such wind hazardous environment.

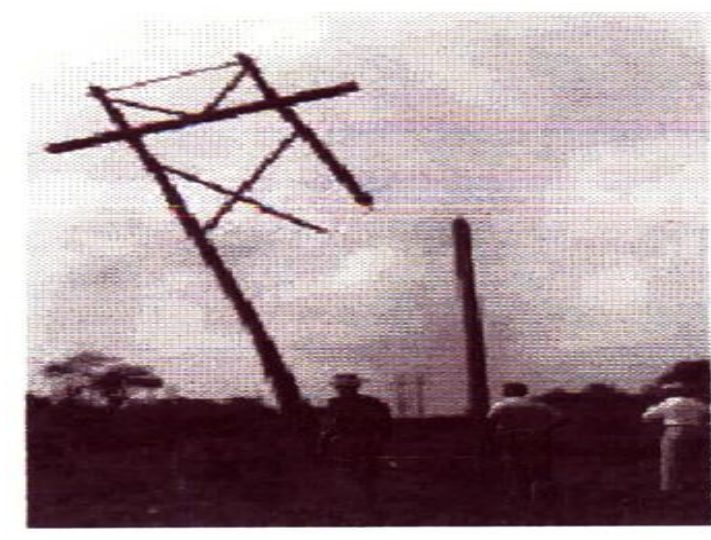

Fig 1: Damage due to strong wind[4]

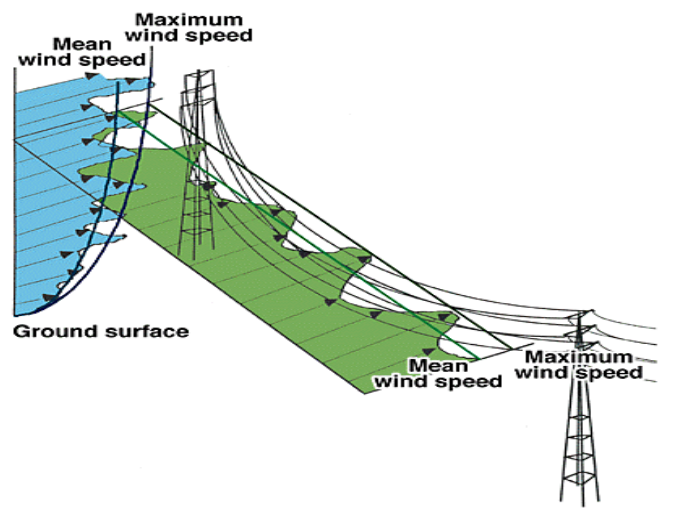

Fig 2:Mean speed and fluctuations of wind[5] 


\section{DEFINITION OF TERMS:}

Wind: Wind is a perceived movement of atmospheric air usually caused by convention or differences in air pressure. The velocity of wind is a result of air pressure difference due to heating and cooling. When a difference in atmospheric pressure exists, air moves from the higher to lower pressure area resulting in wind of various speeds. The resultant effect of these pressure or velocity on any object is referred to as wind effect.

Electric Power Transmission: This is the bulk transporting of electrical energy, from generating station to substations located near demand centers. Power transmission lines are used to transport electrical energy over long distances.

Transmission Line: A Transmission lines refer to electrical transmission lines or cables such as telephone lines and power lines.

Tension: By tension we mean the magnitude of the pulling force exerted by a string, cable, or similar solid object on another object.

Span: Span is the horizontal distance between two electrical support or tower

Transmission Tower: Transmission tower is a tall structure, usually a steel lattice tower, used to provide support to an overhead power line. They come in a wide variety of shapes and sizes. They are used in high voltage AC and DC systems.

Supporting Tower: These are towers carrying electricity from generating stations to demand centers such as homes, schools and industries. They are usually constructed of steel or concrete because of the heavy cables they carry, whereas the power lines in some cities are usually supported on wooden poles as in the case of Nigeria or placed underground as in the case of other countries.

Sag: Sag is defined as the vertical distance between the point where the line is joined to the tower and the lowest point on the line.

Conductor: These are materials that allow the free flow of heat and current. In other words it allow the passage of heat and electricity

Insulator: These are the opposite of conductors. They are materials that do not allow the free flow of heat and electricity on them. They are used in transmission to insulate the conductor from ground. They are usually made of either glass or porcelain and in some cases, ceramic.

\section{LITERATURE REVIEW}

The subject of wind loading on high voltage transmission line was reported in several literatures such as [6-8]. It is discovered that, in all these text, the wind and ice effects are represented by empirical formulae or measurement tables. These formulae and tables are constraint to certain operating, topographical and meteorological conditions and lack generalization. Gust wind loading and sudden strong winds (typhoons) are not included. Recently, few researchers considered the wind effect on tower conductor systems. [9-10] speculate in their studies local wind load on transmission tower conductor systems which was initiated by the unprecedented damage on transmission lines in West Japan caused by Typhoon in 1991. Their results were based on both wind tunnel measurements and numerical simulations. Similar studies were carried out in [11-14]. Some projects $[15,16]$ include the installation of anti-vibrating devices to damp vibrations caused by the conductors exposed to the dynamic load of wind. Studies also shows that the transmission line conductors may have noncircular cross sections designed to minimize the effects of wind-induced motions and vibrations [17]. In a bit to curb with these effect automatic weather stations may be installed on top of transmission towers to monitor both the mechanical loading of the structures due to wind gusts and the thermal dissipation of conductors for ampacity studies [18]. The impacts of the environmental effect on the thermal ratings of overhead conductors were investigated by many researchers such as [1922]. Based on the above review, it is obvious that wind (gust wind) and other environmental factors have drastic effects on the stability of high voltage transmission line.

\section{WIND AND TRANSMISSION LINE}

(a) Sag: Sag literally means to be bending in shape or size. The difference in level between points of supports and the lowest point on the conductor in overhead transmission line is called sag. Sag is one of the adverse effects of wind on transmission line [23].

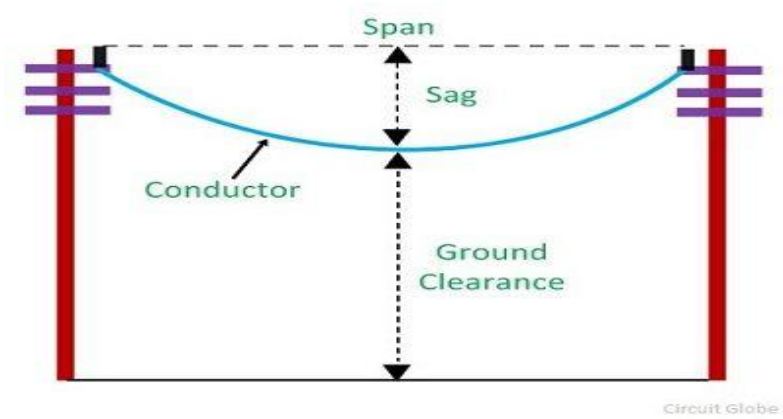

Fig 3: Sag Representation 


\section{EFFECTS OF SAG ON TRANSMISSION LINE}

It causes power failure: When transmission line sag excessively, it is liable of causing instability in the network resulting to power failure. An overheating electrical transmission line sagging into a tree sparked the greatest power failure in the Western United States in 1996.

It reduces excessive tension: If the conductors of a transmission line are too much stretched between the supporting tower or pole, the stress on the conductors may reach an unsafe level and the conductor may break due to excessive pressure (i.e. tension). It is therefore very important that the conductors are under safe tension. In order to permit safe tension in the conductors, the conductors between two supports must not be fully stretched but are allowed to have a dip or sag.

\section{When too much it increases the cost in transmission line:}

The more space in between the transmission towers, the more the transmission line will sag. If there is too much sag in a transmission line, it will increase the amount of conductor used, thereby increasing the cost on conductor more than necessary.

\section{Calculation of sag}

The tension on a suspended conductor is governed by the conductor weight, effects of wind, ice loading and temperature differences. Generally, conductor tension is kept less than $50 \%$ of its ultimate tensile strength. The sag-tension calculation allows calculating the conductor temperature as well as ice and wind loading simultaneously [24]. The value of sag is calculated for two different scenarios - (i) supports at equal levels and (ii) supports at unequal levels.

\section{When supports are at equal levels}

Consider a conductor suspended at supports of equal heights as shown in the figure below. A and B are the support points and $\mathrm{O}$ is the lowest point on the conductor [25].

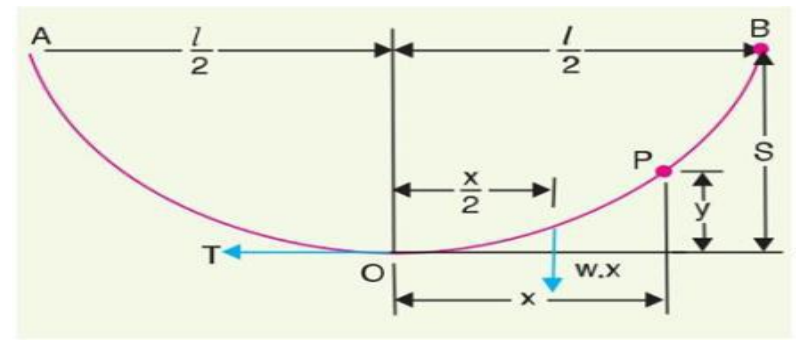

Fig 4: Sag in power line when supports are at equal heights

$$
\begin{aligned}
& \mathrm{l}=\text { length of the conductor span (span length) } \\
& \mathrm{W}=\text { weight per unit length of the conductor } \\
& \mathrm{T}=\text { tension in the conductor }
\end{aligned}
$$

Consider a point $\mathrm{P}$ on the conductor. Considering the lowest point $\mathrm{O}$ as the origin, let the coordinates of point $\mathrm{P}$ be $\mathrm{x}$ and $\mathrm{y}$. Assume the curvature is so small that the curved length is equal to its horizontal projection (i.e. $\mathrm{OP}=\mathrm{x}$ ). The forces acting on the conductor portion OP are -

i. the weight w.x acting at a distance $x / 2$ from the point $\mathrm{O}$

ii. the tension $\mathrm{T}$ acting at the point $\mathrm{O}$

Equating the moments of the two forces about point $\mathrm{O}$, we get,

$\mathrm{T} . \mathrm{y}=\mathrm{w} \cdot \mathrm{x} * \mathrm{x} / 2$

or, $y=w \cdot x^{2} / 2 \mathrm{~T}$

The maximum sag (dip) is represented by the value of $y$ at either of the support points. At support point A,

$\mathrm{x}=1 / 2$ and $\mathrm{y}=\mathrm{S}(\mathrm{sag})$

therefore, $\operatorname{sag} S=w(1 / 2)^{2} / 2 \mathrm{~T}$

therefore, $\operatorname{sag} \mathbf{S}=\mathbf{w} \cdot \mathbf{l}^{2} / \mathbf{8 T}$

\section{When supports are at unequal levels}

We usually experience supports of unequal heights in hilly areas.

Let,

$1=$ length of the conductor span (span length)

$\mathrm{w}=$ weight per unit length of the conductor

$\mathrm{T}=$ tension in the conductor

$\mathrm{h}=$ difference in levels between the two supports

$\mathrm{x}_{1}=$ distance of support at lower level (A) from the origin $\mathrm{O}$

$\mathrm{x}_{2}=$ distance of support at higher level (B) from the origin $\mathrm{O}$

From the above calculation of sag in the previous point,

$$
y=w x^{2} / 2 T
$$

Now, at support $\mathrm{A}, \mathrm{x}=\mathrm{x}_{1}$ and $\mathrm{y}=\mathrm{S}_{1}$ 
Therefore, $S_{1}=w x_{1}{ }^{2} / 2 T$ and $S_{2}=w x_{2}{ }^{2} / 2 T$

Also, $x_{1}+x_{2}=1$

From equation (1)

$$
\frac{w}{2 T}\left(x_{2}+x_{1}\right)\left(x_{2}-x_{1}\right)=\frac{w \times 1}{2 T}\left(x_{2}-x_{1}\right)
$$

But, $S_{2}-S_{1}=h$

Therefore, $h=\frac{w \times 1}{2 T}\left(x_{2}-x_{1}\right)$

Also, $\left(x_{2}-x_{1}\right)=\frac{2 T \times h}{w \times 1}$

Solving equations 1 and 2 we shall have,

$$
x_{1}=\frac{1}{2}-\frac{T \times h}{w \times 1} \quad \text { and } \quad x_{1}=\frac{1}{2}+\frac{T \times h}{w \times 1}
$$

\section{How to prevent excessive sagging of transmission Line}

Transmission lines that sag under heavy use or inrush wind and high temperatures are seen as the basic bane of transmission line operators [26]. Up till now, utilities have had two basic approaches to dealing with line sag [2]. They could either be: Re-engineer the line: re-engineering typically involves (i) reducing the distance between the transmission towers because the more the space between transmission towers or pole, the more the transmission line will sag and (ii) raising tower heights or re-conducting. This is an expensive solution when compared with monitoring it to ensure that sag limits are not breached.

(b) Span Length: The length of a transmission line span is greatly affected by in rush wind. The longer the span gives more sag. Sag is directly proportional to the square of the span length. The force due to wind on the span length is assumed to act horizontally to the conductor. Also the force applied by ice loading is believed to be vertically downwards. Therefore, the total force on the conductor span is the vector sum of the horizontal and vertical forces.

Mathematically,

where,

$$
w_{t}=\sqrt{\left(w+w_{i}\right)^{2}+\left(w_{w}\right)^{2}}
$$

$\mathrm{w}=$ weight of the conductor per unit length

$\mathrm{w}_{\mathrm{i}}=$ weight of the loaded ice per unit length

$\mathrm{W}_{\mathrm{w}}=$ wind force per unit length

But when a conductor has wind as well as ice loading,

i. The conductor sets itself in a plane at an angle $\theta$ to the vertical plane.

Where, $\tan \theta={ }^{w} /\left(w+w_{i}\right)$

ii. In this case, sag is given by $\mathrm{S}=\mathrm{w}_{\mathrm{t}} \cdot \mathrm{I}^{2} / 2 \mathrm{~T}$.

Here, $\mathrm{S}$ is the slant sag, i.e. sag is in the plane where the conductor has set itself. The vertical sag is equal to $\mathrm{S} \cdot \cos \theta$

(c) Tension: Wind load on the conductor will increase the apparent weight of the conductor thereby resulting in an in increase in tension. This increase in resultant load will result in an effective sag in an inclined direction with the two components, horizontal and vertical components. Sag is inversely proportional to the tension in the conductor. Higher tension increases the stress in the insulators and supporting structures. The increase in tension will increase the cable length due to elastic stretch by an amount given by [27]:

$\Delta \mathrm{L}=(\mathrm{T} o-\mathrm{T}) / \mathrm{EA}(\mathrm{ii})$

To $=$ the initial tension in Newton $(\mathrm{N})$

$\mathrm{T}=$ the final tension

$\mathrm{E}=$ the coefficient of elasticity

$\mathrm{A}=$ the cross section of the conductor in meters.

(d) Pole Movement: Strong wind can result to movement in the utility poles or tower. Any movement or shift in the original position of the pole or tower will have the effect of introducing additional length into the span. This can also result to conductor breaking or collapse of adjacent structures. 


\section{CONCLUSION}

Proper analysis of wind environment and its effects is important on high voltage transmission line for the purpose of continuity and quality of electrical services. The study have shown some adverse effects of wind environment on high voltage transmission line span such excessive sag, increase in span length, pole movement, tension e.t.c. It has also been known that sag on conductors increases the length of conductor used for transmission. Also, if the tension of the conductor in a transmission is increased beyond it limit it may get broken and the power transmission of the system get erupt, therefore the need to increase tension by fixing the conductors on pole properly. This will help eliminate possible accident that may arise as a result of sag as living thing including human being can accidently touch line conductors.

\section{REFERENCES}

[1] Quintana, J., Garza, V. and Zamudio, C. Sag-tension calculation program for power substations. In the 42nd Annual Conference of the IEEE Industrial Electronics Society, IEEE, Florence, Italy, 2016, pp 3889-3893. https://doi.org/10.1109/IECON. 2016.7793913

[2] Babar, N., Zulqarnain, M.A., Shahryar S.Q. and Sanaullah, A. Temperature and wind impacts on sag and tension of AAAC overhead transmission line. International journal of advanced and applied science 5 (2), 2018 pp 14

[3] Taleb, M. Ditto M.J. and Bouthiba, T. Performance of short transmission lines models. In the IEEE GCC Conference (GCC), IEEE, Manama, Bahrain, 2006, pp1-7. https://doi.org/10.1109/ IEEEGCC.2006.5686249

[4] Free download from internet

[5] http://criepi.denken.or.jp

[6] Bayliss, C. 1999. Transmission and Distribution Electrical Engineering, Newnes-Elsevier Publisher, 2nd Edition,

[7] Grigsby L. L. 2001. The Electric Power Engineering Handbook, CRC Press-IEEE Press.

[8] Ryan, H. M. 2001. High Voltage Engineering and Testing, IEE, 2nd Edition,

[9] Nakamura H. et al., Studies on local wind and windresistance design of Transmission tower conductor systems, http://criepi.denken.or.jp/en/e_publication/a1999/99seika26.p df
[10] Ishikawa, T. et al., Establishment of recommendations for wind loads on transmission towers - a draft, http://criepi.denken.or.jp/en/e_publication/a2003/03seika38.p df

[11] Ishikawa T. and Nakamura, H. Derivation of gust response factor for transmission steel tower. Abiko Research Laboratory Rep. No. U97100, CRIEPI, 1998.

[12] Ishikawa T. and Nakamura, H. Derivation of gust response factor and maximum horizontal tension of aerial cables. Abiko Research Laboratory Rep. No. U98004, CRIEPI, 1998.

[13] Ishikawa, T. 2003. Study on wind load evaluation method considering the dynamic effect for transmission towers. Structural Mechanics and Earthquake Eng., JSCE, pp I-6

[14] Ishikawa, T. et al., Evaluation techniques of wind load and gust response for overhead transmission lines. CRIEPI review, 48, 2003.

[15] Putnam, E. Country negotiates power line deal, Wausau Daily Herald, 2004, http://www.wausaudailyherald.com/wdhlocal/2940578208574 05.shtml.

[16] National Power Transmission Co. "Transelectrica” SA, Romania, Project No. 33354, 2004, http://www.ebrd.com/projects/psd/psd2004/33354.htm.

[17] Peterson Jr A. J.. and Hoffmann, S. 2003 Transmission line conductor design comes of age, http://www.findarticles.com/articles/mi_m0CXO/

is_6_55/ai_103697698.

[18] Monitoring Transmission Lines, VAISALA, Finland, www.vaisala.com/DynaGen_Attachments/Att33124/VN165 p19.pdf.

[19] Daconti, J. R. 2003. Increasing power transfer capability of existing transmission lines, Power Technologies, Inc., http://www.ewh.ieee.org/r1/schenectady/feb21_2003_lecture. pdf.

[20] Raniga J. and Rayudu., R. K. Stretching transmission line capabilities - A transpower investigation, Institution of 
International Journal of Science and Engineering Applications

Volume 8-Issue 10,455-460, 2019, ISSN:-2319-7560

Professional Engineers, NewZealand, http://www.cfacs.co.nz/download/Dlripenz.pdf.

[21] For Uprating Overhead Lines, Shaw Power Technologies, Inc.,

2004

www.shawgrp.com/PTI/consulting/transmission/rating_monit or.cfm.

[22] Upgrading Transmission Capacity for Wholesale Electric Power

Trade,

www.eia.doe.gov/cneaf/pubs_html_feat_trans_capacity/w_sal e.html.

[23] www.eng.uwi.tt
[24] Mehta, V. K. and Mehta, R. 2005. Principles of power system. S. Chand Publisher, Ram Nagar, New Delhi, India. 4th edition.

[25] www.electricaleasy.com

[26] Electric transmission week 2004, publisher of power daily.

[27] Kamboj S. and Dahiya, R. Case study to estimate the sag in overhead conductors using GPS to observe the effect of span length. In the IEEE PES TandD Conference and Exposition, IEEE, Chicago, IL, USA; 2014, pp 1-4. https://doi.org/10.1109/ TDC.2014.6863337 